\title{
Orléans - 9 quai du Roi
}

$n^{\circ} 068554$

Sébastien Jesset

\section{(2) OpenEdition}

Journals

Édition électronique

URL : http://journals.openedition.org/adlfi/13870

ISSN : 2114-0502

Éditeur

Ministère de la culture

Référence électronique

Sébastien Jesset, «Orléans - 9 quai du Roi », ADLFI. Archéologie de la France - Informations [En ligne], Centre, mis en ligne le 19 novembre 2014, consulté le 02 mai 2019. URL : http:// journals.openedition.org/adlfi/13870

Ce document a été généré automatiquement le 2 mai 2019.

(c) Ministère de la Culture et de la Communication, CNRS 


\title{
Orléans - 9 quai du Roi
}

\author{
$\mathrm{n}^{\circ} 068554$
}

\section{Sébastien Jesset}

Lien Atlas (MCC) :

http://atlas.patrimoines.culture.fr/atlas/trunk/index.php?

ap_theme=DOM_2.01.02\&ap_bbox=1.874;47.813;1.949;47.933

1 A l'instar des nombreuses découvertes archéologiques faites à Orléans au XIX ${ }^{\mathrm{e}}$ s., c'est au cours de travaux édilitaires visant à désenclaver la ville de l'Ancien Régime qu'ont été mis au jour les vestiges du théâtre antique : la création en 1821 d'une promenade longeant la partie orientale du rempart $d u x^{e}$ s. et les travaux de nivellement s'y rattachant sont à l'origine de cette découverte. Dans la précipitation des terrassements, commandés par la réalisation simultanée du Quai du Roi, un plan des vestiges fut rapidement dressé, correspondant à la moitié occidentale du monument. Il s'agit là du seul témoin de cette découverte qui nous soit parvenu. Aucun des éléments architecturaux mis au jour n'a été conservé en place, les déblais et les matériaux de construction du théâtre ayant été immédiatement réemployés dans la construction du Quai du Roi. Cette information s'est trouvée vérifiée avec les sondages archéologiques réalisés en avril 1997 à l'angle des rues de l'Abreuvoir et de la Croix Pêchée. La partie du quai mise en évidence à cette occasion recelait des blocs monumentaux : corniches, dalles de sol, grand appareil...

2 Comme la plupart des édifices de ce type, le théâtre antique d'Orléans a marqué le paysage durablement. La topographie des lieux, le parcellaire de ce secteur, les documents historiques manuscrits ou iconographiques, sont autant de preuves accumulées permettant d'appréhender sa localisation et sa forme. Il convient de restituer un édifice installé à flanc de coteau, avec un mur d'arrière-scène (postscaenium) situé à une quinzaine de mètres de la berge du fleuve. Le relief est de ce fait utilisé au mieux pour installer les gradins (cavea). La proximité de la Loire et l'orientation du monument confèrent à la Loire, et à la plaine du Val, un rôle d'arrière-plan qui devait sans doute participer au jeu scénique et à la mise en perspective des spectacles. 
3 Les travaux archéologiques menés en 1997 confirment la faible distance séparant l'édifice de la Loire. Aucun aménagement de berge concernant la période gallo-romaine n'a été mis au jour, ce qui pourrait accréditer l'existence d'une simple grève devant le théâtre. Les formes et le découpage du parcellaire se calquent sur la conformation du théâtre. La rue de l'Abreuvoir reprend la courbure de l'orchestra. Un chemin assure la permanence de l'emplacement d'un couloir central (vomitoire). La rue de la Croix-Pêchée peut, quant à elle, figurer un accès latéral au théâtre, qui trouve son pendant sur le flanc ouest. Sur le plan de la fin $d u X^{X} I_{I}{ }^{e} s$. est figuré un tronçon du mur de postscaenium encore en élévation. Son existence suppose que la destruction du théâtre antique ne fut peut-être pas aussi rapide que l'on se plaît à le dire. Preuve en est un texte du XVII ${ }^{\mathrm{e}}$ s. qui rapporte la destruction de parties de mur en élévation du théâtre gênant l'installation du séchoir à linge de l'Hôtel-Dieu.

4 L'édifice de spectacle implanté à l'écart de l'agglomération gallo-romaine, à proximité d'une nécropole, est encore en grande partie méconnu. La date de sa fondation, sa forme exacte, son environnement précis nous échappent très largement, et sont autant de questions qui alimenteront les recherches futures.

\section{INDEX}

Index géographique : Centre, Loiret (45), Orléans

Index chronologique : Gallo-romain

Mots-clés : théâtre

operation Évaluation archéologique (EV) 